\title{
EDITORIAL
}

\section{Sobre trocas de experiências em ensino médico}

s principais fontes de inovações no
ensino médico têm sido: as aspira-
ções dos docentes e diretores no sentido de melhorar os cursos; os resultados de avaliações promovidas por comissões de currículo; as "pressões" dos alunos; e as necessidades da sociedade.

Nas últimas décadas, as aspirações dos docentes e alunos foram "alimentadas" pela facilidade de acesso a informações sobre os resultados de introdução de inovações em escolas médicas de todo o mundo, incluindo a possibilidade de observação in loco do funcionamento de novas metodologias de ensino e avaliação, a participação em congressos e workshops sobre ensino médico, e a possibilidade de acesso a material escrito e de troca de informações e experiências pela Internet.

A Faculdade de Medicina de Ribeirão Preto (FMRP) começou a funcionar no início da década de 50, com currículo estruturado de acordo com o "modelo americano" mais valorizado na época. Apesar de, em poucos anos de funcionamento, a nossa escola ter atingido lugar de destaque, como centro de excelência em ensino, pesquisa e assistência, tanto no Brasil como no exterior, há registros de que, pelo menos a partir da década de 70 , surgiu a necessidade de inovar para melhorar.

Assim, a FMRP passou a se preocupar com o aprimoramento didático e pedagógico de seus membros. Em diversas épocas, foi dada a alguns docentes de nossa escola a oportunidade de frequentar cursos e seminários do NUTES/CLATES. Em 1975, a Organização Mundial da Saúde apoiou a visita de três professores a diversas escolas médicas do exterior. A participação da FMRP nas reuniões, nos Congres- sos Brasileiros de Educação Médica, organizados pela $A B E M$ e em eventos regionais foi e tem sido constantemente estimulada (uma das quais foi realizada em Ribeirão Preto). Também foi realizado aqui o I Forum Paulista de Avaliação do Ensino Médico, da Comissão Interinstitucional de Avaliação do Ensino Médico (CINAEM), com a coordenação de um representante do Conselho Regional de Medicina do Estado de São Paulo e da Comissão de Graduação da FMRP, com grande envolvimento de todos os seus membros.

Em 1990, através de programa para aperfeiçoamento do ensino de graduação, a Universidade de São Paulo e o Banco Interamericano de Desenvolvimento (Convênio USP/BID) propiciaram a um membro do corpo docente da FMRP um estágio de três meses em escolas médicas do Hemisfério Norte. Depois disso, outro docente teve a oportunidade de ingressar no curso de Mestrado em Ensino Médico da Universidade de Dundee, e diversos outros participaram de cursos, predominantemente na Southern Illinois School of Medicine, e de congressos. Nos últimos anos, professores da FMRP têm visitado escolas médicas de outros continentes e há sempre, pelo menos um representante da FMRP nas Ottawa Conferences for Medical Education e nos congressos da Association for Medical Education in Europe (AMEE).

Assim como a participação de brasileiros, a participação de docentes de outros países da América Latina nas reuniões da AMEE tem aumentado nos últimos anos. Em 1999, participaram da AMEE Conference, realizada em Linkoping, Suécia, professores de diversos países da América Latina, que apresentaram dezoito (18) trabalhos, oralmente, ou sob a forma de poster, seis dos quais elaborados na FMRP 
(predominantemente pelo Grupo de Trabalho para Avaliação da Comissão de Graduação e pelo Centro de Apoio Educacional e Psicológico (CAEP)).

Na ocasião do evento, foi organizado o Latin American Group Meeting, e está sendo planejado outro encontro para agosto próximo em Beer Sheva, Israel.

Vale uma reflexão sobre as causas e as eventuais vantagens e desvantagens da globalização no ensino médico. Por que nós, docentes de escolas médicas da América Latina, que raramente discutimos ensino médico com colegas do mesmo departamento, gostamos de discutir nossas inquietações com colegas de outros continentes, que convivem com realidades diferentes? Será que temos muitos problemas em comum? Será que gostamos de fasciná-los com o fato de que, como atendemos grande número de pacientes, não temos tanta necessidade de pacientes padronizados para nossas aulas práticas? Por que razão nós sentimos mais acolhidos nesses eventos do que em algumas reuniões nacionais? Será porque algumas posições de nosso grupo, como no caso da avaliação da CINAEM, são ouvidas com estranheza pelos colegas de outras escolas médicas brasileiras, o que chega a ocasionar fortes questionamentos de nossos alunos? Será porque nossas escolas foram criadas de acordo com modelos do Hemisfério Norte e é natural que nós queiramos conhecer as necessárias adaptações que se fizeram para resolver os problemas que foram surgindo? Será porque as pesquisas que se realizam na área de ensino podem nos trazer informações interessantes?

E quais seriam as motivações dos organizadores do evento? Será que a Europa pretende mais uma vez "colonizar" a América Latina? Será que estão dispostos a abrir caminho para que possamos publicar os resultados de nossas pesquisas sobre ensino médico em veículos de circulação mundial? Ou será que estão interessados somente em ampliar o número de sócios?

Estimulados a colaborar na agregação do Latin American Group, pensamos em organizar um workshop em Ribeirão Preto, visando, principalmente, a difusão de conhecimentos de ensino médico entre nossos pós-graduandos, mas, antes de levar adiante a idéia, formalizamos à AMEE algumas de nossas questões, cujas respostas aguardamos. Esperamos que, se for realizado, esse evento desperte o interesse dos professores da FMRP e de outras escolas médicas brasileiras.

\section{Maria de Lourdes Veronese Rodrigues Carlos Eli Piccinato José Fernando de Castro Figueiredo Docentes da FMRP-USP}

